\title{
La Grèce moderne : une carte en 20 feuilles réalisée par le Service historique de l'armée de terre française, éditée en 1852
}

\section{Panagiota Anagnostou et Maria Zerva}

\section{CpenEdition}

Journals

Édition électronique

URL : http://journals.openedition.org/rbnu/676

DOI : $10.4000 /$ rbnu. 676

ISSN : 2679-6104

Éditeur

Bibliothèque nationale et universitaire de Strasbourg

Édition imprimée

Date de publication : 1 novembre 2017

Pagination : 52-55

ISBN : 9782859230678

ISSN : 2109-2761

Référence électronique

Panagiota Anagnostou et Maria Zerva, « La Grèce moderne : une carte en 20 feuilles réalisée par le Service historique de l'armée de terre française, éditée en 1852 », La Revue de la BNU [En ligne], 16 | 2017, mis en ligne le 01 juillet 2019, consulté le 28 décembre 2020. URL : http:// journals.openedition.org/rbnu/676; DOI : https://doi.org/10.4000/rbnu.676 


\section{GRÈCE \\ LA GRÈCE MODERNE : UNE CARTE EN 20 FEUILLES RÉALISÉE PAR LE SERVICE HISTORIQUE DE L'ARMÉE DE TERRE FRANÇAISE, ÉDITÉE EN 1852 \\ PAR PANAGIOTA ANAGNOSTOU \\ ET MARIA ZERVA}

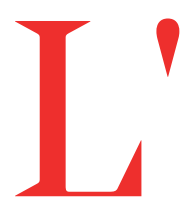

État moderne, cette entreprise politique de caractère institutionnel qui détient le monopole de la violence légitime, selon la fameuse définition de Max Weber, ne peut exister qu'à l'intérieur d'un territoire géographique déterminable ${ }^{1}$. Dans le cas de la Grèce moderne, la quête de la délimitation des frontières dura plus d'un siècle, depuis l'indépendance du pays visà-vis de l'Empire ottoman, reconnue par les grandes puissances et le sultan lors de la conférence de Londres en 1830, jusqu'à l'annexion du Dodécanèse (1947), appartenant auparavant à l'Italie, après la défaite de cette dernière à l'issue de la Seconde Guerre mondiale.

La question du territoire devint de première importance pour le pays et l'entraîna dans une série de guerres. Au-delà d'une dimension irrédentiste, elle fut, avec la profondeur historique et le besoin d'une continuité culturelle, un des enjeux principaux de la construction identitaire grecque, et ce d'autant plus que le $19^{\mathrm{e}}$ siècle fut celui de la montée des nationalismes dans toute la région des Balkans, comme ailleurs en Europe. Les rapports de la Grèce moderne avec le passé furent marqués par l'Antiquité, à tel point que les

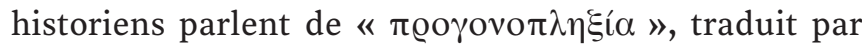
Richard Clogg par « ancestoritis », une obsession pour les ancêtres ${ }^{2}$. La réhabilitation de Byzance, souvent attribuée à l'œuvre du professeur de l'Université
d'Athènes Constantin Paparrigopoulos (l'Histoire de la nation hellène, parue entre 1860 et 1874), fournit l'inclusion de cette période également dans le récit identitaire grec. La prise de Constantinople en 1453 devint ainsi le symbole de ce que les Grecs nommèrent le « joug ottoman ».

Au niveau de la continuité culturelle, les éléments incontournables furent la religion et la langue. En ce qui concerne le christianisme orthodoxe, il fut inextricablement lié à l'identité grecque avant même la construction de l'État, au sein de l'Empire ottoman avec son organisation en millets ${ }^{3}$, et il continua à occuper une place de choix avec la proclamation de l'« autocéphalie » ${ }^{4}$ de l'Église nationale grecque en 1833. Il devint la « religion dominante " selon la constitution grecque. En revanche, la question de la forme de la langue grecque à ériger en langue officielle provoqua de vifs débats qui durèrent jusqu'à la deuxième moitié du $20^{\mathrm{e}}$ siècle et divisèrent les intellectuels entre l'adoption de la «katharevousa », la langue "purifiée », et celle de la langue communément parlée, nommée démotique ${ }^{5}$.

Antiquité, Byzance, religion et langue maintinrent un rapport étroit avec la délimitation des frontières, puisqu'une grande partie des villes antiques et byzantines, mais surtout de la population orthodoxe et/ou hellénophone resta à l'extérieur des frontières de 1830. La quête identitaire grecque se concrétisa, tout au long du $19^{\mathrm{e}}$ siècle, au travers de la construction 
politique fédératrice de la « Grande Idée », le rêve d'une Grande Grèce de « cinq mers et de deux continents " ${ }^{6}$. La Grande Idée mobilisa les troupes, entraîna les populations, définit des héros et des victimes, pour prendre fin avec la " Grande Catastrophe », la défaite grecque en Asie Mineure face aux troupes kémalistes, défaite entérinée par le traité de Lausanne de 1923.

La carte de la Grèce de 1852 en 20 feuilles, réalisée par le Service historique de l'armée de terre française et présente dans les collections de la BNU (on a reproduit ici le tableau d'assemblage), donne à voir les premières frontières du jeune État, avant l'annexion des îles Ioniennes en 1864, de la Thessalie en 1881, de la Crète, de l'Épire et de la Macédoine en 1913, de la Thrace en 1919 et du Dodécanèse en 1947. La cartographie française concernant la Grèce connut un essor dès la fin du $18^{\mathrm{e}}$ siècle. Géographes, cartographes, archéologues, graveurs et voyageurs collaborèrent, échangèrent des informations et des compétences pour illustrer, par exemple, l'atlas qui accompagna Le Voyage du jeune Anacharsis en Grèce, dans le milieu du quatrième siècle avant l'ère vulgaire ${ }^{7}$, récit de voyage fictif de l'abbé Barthélemy, l'ouvrage le plus lu de son époque ${ }^{8}$. L'atlas fut dirigé par Barbié du Bocage, qui joua un rôle de premier ordre dans la liaison entre Grèce antique et moderne. Jusqu'à sa mort en 1825, plus d'un intellectuel passaient dans l'atelier du cartographe pour se procurer des cartes en vue de leur voyage en Grèce, puis lui rapportaient corrections et précisions issues de leurs périples à leur retour. Le voyage en Grèce fut à cette époque une étape importante afin de compléter l'éducation classique de tout jeune aristocrate.

Barbié du Bocage travailla pour le ministère de l'Intérieur, le ministère de l'Extérieur et le ministère de la Guerre, dessina la carte de la Morée en 1802, et participa à la pensée géographique militaire qui connut un essor au $19^{\text {e }}$ siècle $^{9}$. L'armée française intervint militairement en Grèce en 1828, aux côtés des insurgés, pendant la lutte pour l'indépendance. Comme lors de l'expédition d'Égypte trente ans plus tôt, l'expédition de Morée fut complétée par une grande entreprise scientifique qui rassembla botanistes, géologues, géographes, archéologues et architectes et prépara la fondation, en 1846, de l'École française d'Athènes, première école étrangère d'archéologie en Grèce. Au-delà de l'importance des autres résultats scientifiques de l'expédition de Morée, les cartes de la
Grèce furent rectifiées et des précisions importantes furent apportées. La carte de 1852 pourrait ainsi être une réédition commandée par le Second Empire.

Parmi les autres documents cartographiques concernant la Grèce et disponibles à la BNU, cette carte de 1852 étonne par la richesse des informations qu'elle fournit. D'abord, les précisions d'intérêt cartographique : principales montagnes avec leurs hauteurs au-dessus du niveau de la mer (avec de très légères divergences avec les données actuelles), fleuves, villes, villages, maisons isolées, moulins, sources d'eau, monastères, ruines (avec une division entre ruines antiques et ruines byzantines, françaises ou vénitiennes). Ensuite, des données administratives et démographiques y figurent : divisions en nomes, éparchies et dèmes ${ }^{10}$ avec leurs frontières et leurs populations, l'expédition de Morée ayant déjà effectué le premier recensement français de la population grecque en 1829. Enfin, les toponymes sont mentionnés avec leur double ou triple nom ${ }^{11}$ et une «note sur l'orthographe et la prononciation des noms de la carte " complète le document.

La feuille $\mathrm{n}^{\circ} 10$, qui contient les données administratives et démographiques, présente également le plan d'Athènes, proclamée capitale du royaume de Grèce par le roi bavarois Othon $\mathrm{I}^{\text {er }}$ en 1834. Ville quasiment inhabitée, Athènes fut reconstruite par des architectes bavarois qui amenèrent le style néoclassique dans le pays qui l'avait inspiré. Le plan sépare monuments antiques et modernes et on peut y voir l'Acropole bien sûr, avec le Parthénon et le théâtre d'Hérode Atticus, mais aussi le Palais royal et l'Académie, ainsi que la Métropole d'Athènes, église dont la construction dura vingt ans (1842-1862).

La carte de 1852, réalisée à une période de grands changements, concernant tant les frontières grecques que la ville d'Athènes, est donc un document de valeur historique incontestable, illustrant une étape de la construction de la Grèce moderne. 


\section{NOTES}

1- Max Weber, Économie et société, Paris, Agora, 2003, p. 96-100

2- Richard Clogg, A Concise History of Greece, Cambridge, Cambridge University Press, 1992, p. 2

3- La gouvernance de l'Empire ottoman reposait sur le système des millets, un découpage administratif sur la base de la religion. En termes de nombre, le deuxième plus grand millet, après le millet dominant (musulman), était le millet orthodoxe, composé des Grecs, Bulgares, Roumains, Serbes, etc. En tête du millet orthodoxe, le Patriarcat CEcuménique de Constantinople devint une institution religieuse supra-ethnique et politique, assumant la collecte des taxes, le maintien de la sécurité interne, le rôle éducatif et judiciaire pour ses sujets.

4- Il s'agit de l'autonomie de l'Église grecque par rapport au patriarcat de Constantinople. Pour une analyse détaillée de l'histoire de l'Église grecque, voir Isabelle Dépret, Église orthodoxe et histoire en Grèce contemporaine, versions officielles et controverses historiographiques, Paris, L'Harmattan, 2009.

5- Sur la controverse autour de la langue, voir Peter Mackridge, Language and National Identity in Greece, 1766-1976, Oxford, Oxford University Press, 2009.

6- Les frontières nationales imaginaires s'étendaient de la ligne d'Aimos au cap Ténare, au sud du Péloponnèse, et de l'Adriatique à la mer Noire et aux monts Taurus, au sud de la Turquie actuelle ; voir Nicolas Svoronos, Histoire de la Grèce moderne, Paris, PUF, 1972³ , p. 51.

7- Le récit de Jean-Jacques Barthélemy est disponible à la BNU et sur Gallica (7 volumes). Sa première édition date de 1788 .

8- Jean-Yves Guiomar et Marie-Thérèse Lorain, «La carte de Grèce de Rigas et le nom de la Grèce ", in Annales historiques de la Révolution française [en ligne], $\mathrm{n}^{\circ} 319$, janvier-mars 2000 (disponible sur http://ahrf.revues.org/106, consulté le 12 juillet 2017).

9- Philippe Boulanger, « Renseignement géographique et culture militaire ", in Hérodote, $\mathrm{n}^{\circ} 140,2011$, p. $47-63$

10- Il s'agit du découpage administratif de l'époque, proche des divisions actuelles en région, département et municipalité.

11- Sur les noms de lieux et leur adaptation pour l'usage français dès la seconde moitié du MoyenÂge, voir Jean Longnon, « Les noms de lieu de la Grèce franque ", in Journal des savants, juilletseptembre 1960, p. 97-110.
$F=5$

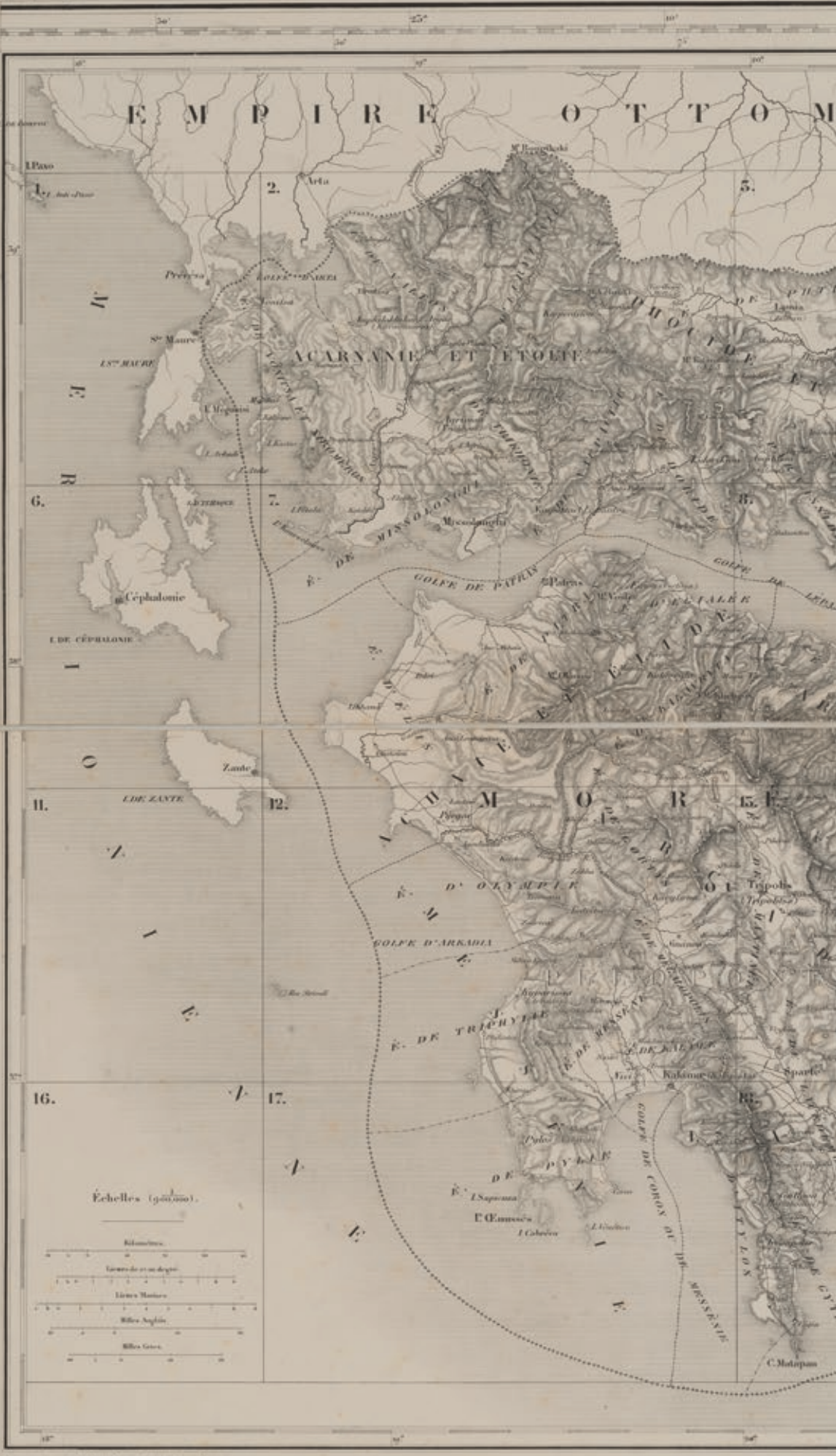




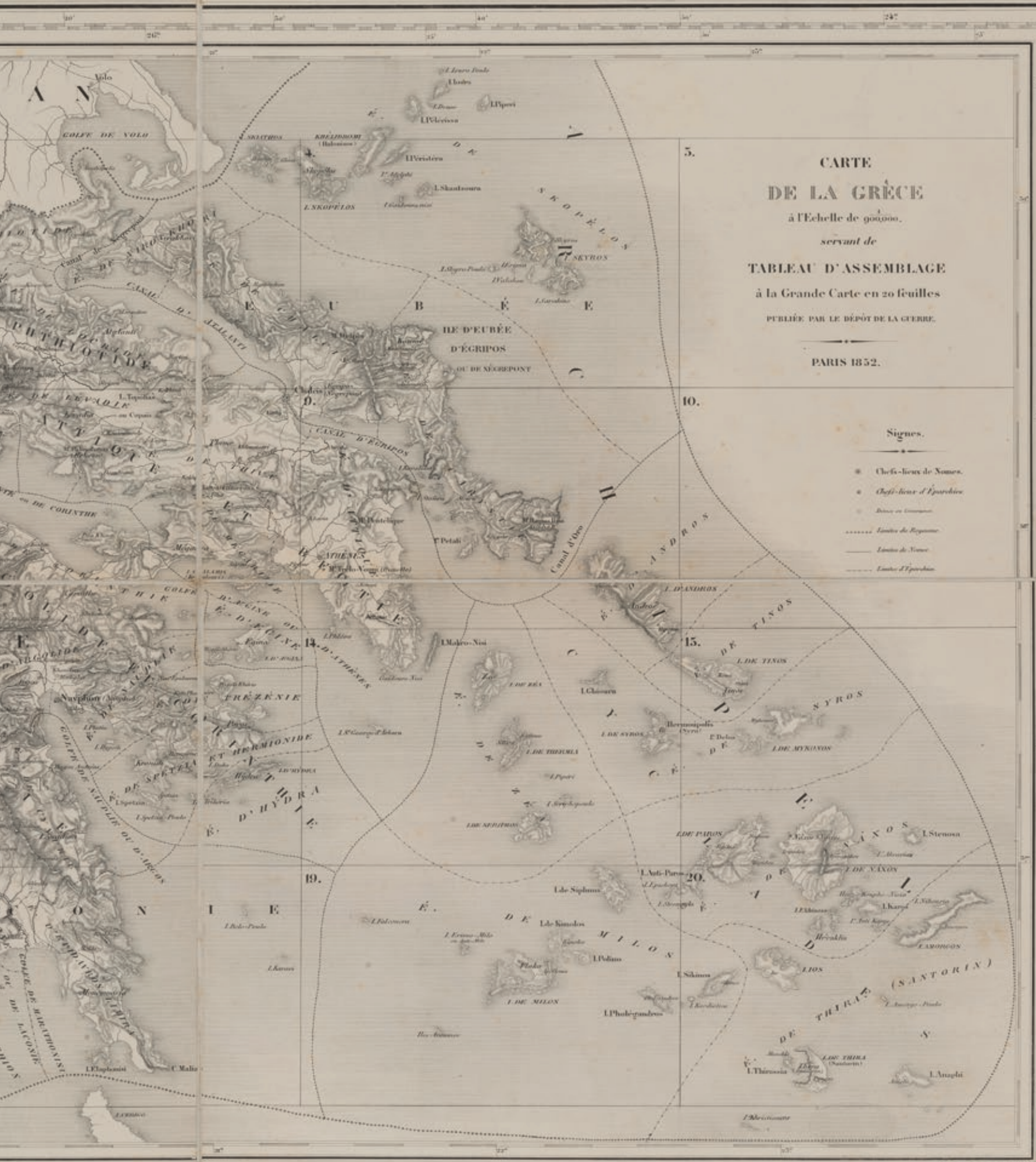

